\title{
A PALAVRA COMO ARMA NA LUTA PELA INDEPENDÊNCIA: REFLEXÕES SOBRE A POESIA ANTICOLONIAL NOS PAÍSES AFRICANOS DE LÍNGUA PORTUGUESA
}

Luana Soares de Souza (UNEMAT)

RESUMO: A palavra possibilita a reconstrução do passado e a projeção do futuro imaginado. O poeta cicatriza as feridas abertas do passado, mas também relembra, acende e revive o passado para projetar o futuro. Nega o passado reafirmando-o. Esse processo, construído pelo poeta, está recheado de camadas ideológicas. Essa tensão sobre o presente e o passado, em busca do devir, se solidifica a partir da realidade e das contradições sociais. Os poetas que viveram o período das lutas pela independência dos países africanos de língua portuguesa enveredaram sobre os caminhos tortuosos do passado e do presente. Entender a colonização, suas formas de opressão e de dominação, foi o passo inicial para produzir uma literatura que pudesse questionar o espaço colonial. A palavra poética-profética, portanto, foi utilizada como arma na luta pela independência. Este artigo busca refletir sobre a poesia anticolonial e sobre como a literatura pode contribuir nos processos históricos de luta e resistência. Para tanto, alguns poemas - de escritores que viveram no período das lutas pela independência - serão analisados, considerando a construção ética e estética da poesia anticolonial.

Palavras-chave: Poesia anticolonial; Países africanos de língua portuguesa; colonização portuguesa.

ABSTRACT: The word enables the reconstruction of the past and the projection of the imagined future. The poet heals from the open wounds of the past, but also remembers, lights up and revives the past to project the future. Deny the past by reaffirming it. This process, built by the poet, is filled with ideological layers. This tension over the present and the past, in search of becoming, solidifies from reality and social contradictions. The poets who lived the period of struggles for the independence of the Portuguese-speaking African countries embarked on the tortuous paths of the past and the present. Understanding colonization, its forms of oppression and domination, was the initial 
step to produce a literature that could question the colonial space. The poetic-prophetic word, therefore, was used as a weapon in the struggle for independence. This article seeks to reflect on anticolonial poetry and on how literature can contribute to historical processes of struggle and resistance. For that, some poems - from writers who lived in the period of the struggles for independence - will be analyzed, considering the ethical and aesthetic construction of anticolonial poetry.

Keywords: Anti-colonial poetry; Portuguese-speaking African countries; Portuguese colonization.

Para falar de poesia é preciso falar de história, pois ambas são indissociáveis. Segundo Octavio Paz (1982, p.226), "o poema, ser de palavras, vai mais além das palavras e a história não esgota o sentido do poema; mas o poema não teria sentido - nem sequer existência - sem a história, sem a comunidade que o alimenta [...]". Portanto, para refletir sobre a poesia anticolonial dos países africanos de língua portuguesa é necessário recorrer ao passado e à história dessas comunidades, para entender como a literatura incide nas realidades, nas lutas e nos conflitos históricos.

No século XX, nos países africanos de língua portuguesa, vários grupos começaram a se organizar para lutar contra o colonialismo português. Nesse processo, vários quadros se destacaram: Amilcar Cabral, na Guiné-Bissau e Cabo Verde, Agostinho Neto, em Angola, e Samora Moises Machel, em Moçambique. Esses líderes incitaram as primeiras lutas organizadas contra o colonialismo. 
Na Guiné-Bissau e em Cabo Verde, Amilcar Cabral inicia os confrontos armados contra a metrópole portuguesa fundand o o PAIGC1 ${ }^{1}$, em 1959. Em janeiro de 1966, ele participa da Conferência Tricontinental em Havana que visava unificar todos os movimentos revolucionários armados, a fim de unirem forças contra toda forma de opressão (imperialismo - colonialismo). Cabral, inspirado pelas ideias revolucionárias dos cubanos, que alguns anos antes tinham se libertado da dominação de Fulgêncio Batista², inicia a organização das guerrilhas armadas juntamente com a população que sofria com o colonialismo.

Já em Angola, o cenário político durante as lutas pela libertação foi turbulento. Surgiram três organizações que lutavam pela independência: $\mathrm{MPLA}^{3}, \mathrm{FNLA}^{4}$ e a UNITA ${ }^{5}$. Essas organizações eram financiadas por países que tinham algum interesse político e/ou econômico em Angola. O MPLA tinha relações com o bloco socialista: URSS ${ }^{6}$ e Cuba; a FNLA tinha ligação com os Estados Unidos; a UNITA era financiada pela

1 Partido Africano para a Independência da Guiné e Cabo Verde

2 Fulgêncio Batista foi presidente de Cuba em 1940 até 1944. Em 1952 voltou ao governo de Cuba, porém, foi deposto pelas guerrilhas populares comandadas por Fidel Castro e Che Guevara.

3 Movimento pela Libertação de Angola

4 Frente Nacional de Libertação de Angola

5 União Nacional Total pela Independência de Angola

6 União das Repúblicas Socialistas Soviéticas 
África do Sul, que mantinha o apartheid. Nesse período, enquanto a União Soviética e Cuba financiavam as lutas pela independência, os Estados Unidos financiavam as Ditaduras Militares por toda América Latina. O MPLA era o movimento mais antigo e foi um dos pioneiros nas lutas revolucionárias. Segundo Paulo Visentini (2012, p.51), "a prisão de Agostinho Neto, um respeitado apoiador do MPLA, em junho de 1960, fomentou uma das primeiras manifestações angolanas em desafio ao sistema colonial português".

Em Moçambique, o grupo que liderou as lutas pela independência foi a FRELIMO . Essa Frente surgiu a partir de três organizações que se fundiram: UDENAMO ${ }^{8}, \mathrm{MANU}^{9}$ e UNAMI $^{10}$.

É possível perceber, portanto, que as lutas dos países africanos de língua portuguesa pela independência tinham objetivos comuns: eram revolucionárias, organizadas e armadas. As organizações anticoloniais possuíam táticas e estratégias muito semelhantes. Assim como a luta armada se intensificou nos PALOP, também surgiu outra forma de peleja: a luta com as palavras. Nesse período surgiram escritores

\footnotetext{
7 Frente de Luta pela Libertação de Moçambique

8 União Democrática Nacional de Moçambique

9 Mozambique African National Union

10 União Nacional Africana de Moçambique Independente
} 
como Noémia de Sousa, Rui Knopfli, Antônio Jacinto, Duarte Galvão, Albuquerque Freire, Alda Lara, Osvaldo Alcântara, Agostinho Neto, Rui Nogar e José Craveirinha.

As lutas pela independência geraram uma articulação dos intelectuais que desejavam um mundo liberto da opressão e do colonialismo. A criação literária proporcionou uma intervenção mais organizada no cenário político de Moçambique e, consequentemente, o desejo do novo, expresso em poesia, transbordou para a realidade. As preocupações, vontades e sonhos serão pautados na escrita poética. A literatura incide no plano físico e nas lutas armadas como combustão para transgressão da ordem imposta pelo sistema colonial.

A literatura foi fundamental no processo de independência, pois ela anunciava o devir de um novo mundo. José Cabaço comenta que a literatura do período colonial se afirmou "pela denúncia ficcional das iniquidades, das humilhações e das brutalidades da ocupação, alimentou na imaginação dos nacionalistas urbanos a utopia de um amanhã de liberdade que se anunciava"(2009, p.287).

Essa geração, que lutava contra o colonialismo, teve seu grito silenciado pela colonização portuguesa. Em Moçambique, por exemplo, vários intelectuais foram 
censurados porque suas produções continham alto teor revolucionário. José Craveirinha formou, juntamente com “[...] Rui Nogar, Malangatana Valente, Luís Bernardo Honwana e Orlando Mendes, aquela que poderemos designar por geração do silêncio. Silenciada embora, esta geração sempre se afirmou pela recusa do sistema colonial [...]" (LEITE, 1991, p.21). Mesmo silenciados, os poetas moçambicanos expressavam em seus textos poéticos o desejo pela liberdade. Os temas abordados na escrita dos poetas que viveram no período colonial convergiam para o anseio de construção coletiva por uma nova sociedade.

Se na literatura os poetas foram silenciados pela metrópole, no espaço moçambicano centenas de trabalhadores foram fortemente reprimidos ao se manifestarem. Cabaço (2009, p.221) relata que "nas áreas rurais, os protestos e as reivindicações dos trabalhadores eram violenta e exemplarmente silenciados. Imperava a política de bastão".

É possível perceber, portanto, que a poesia tem uma íntima relação com a história. O homem que faz versos e conduz as palavras para o território poético, transfundindo significados, está localizado em um determinado tempo. Esse tempo, no caso de Moçambique, Angola, etc., marca a luta pela independência. Nessa perspectiva, Alfredo Bosi (2000, p.140) 
comenta que "um poeta não vive em uma outra História, distante ou alheia à história da formação social em que escreve". Logo, nota-se que a poesia não pode ser distanciada das bases materiais de produção do poeta, pois o mesmo vive em uma sociedade, da qual contrai relações sociais, que contribuem no processo de confecção da sua obra.

Logo, é impossível dissociar história e poesia no contexto em que escrevem os escritores que lutam pela independência nos países africanos de língua portuguesa. As trincheiras se localizam também nos versos. Os escritores dos PALOP começam a formular estratégias estéticas para combater o colonialismo através da palavra. A literatura anticolonial possui não apenas uma afirmação política e ideológica, mas também uma construção estética e estrutural. Nesse sentido, Walter Benjamin (2012) comenta que toda obra produzida possui uma tendência política e uma tendência literária.

[...] a tendência de uma obra literária só pode ser correta do ponto de vista político quando for também correta do ponto de vista literário. Isso significa que a tendência politicamente correta inclui uma tendência literária. $E$ já acrescento imediatamente que é essa tendência literária contida implícita ou explicitamente em toda tendência política correta - é ela, e somente ela, que determina a qualidade da obra. (BENJAMIN, 2012, p.130) 
Assim sendo, o "valor" de uma obra é determinado pela sua construção estética. No entanto, toda construção estética carrega um "valor" político. A tendência política dos intelectuais desse momento histórico, nos países africanos de língua portuguesa, é explicitada a cada verso: uma defesa irrestrita pela liberdade criada na construção de imagens, na pele da palavra, no som do silêncio, na pausa e no ritmo, misturando forma e conteúdo, tendência literária e tendência política. No entanto, é apenas a construção estética e o trabalho com a palavra que determina a "qualidade da obra", segundo Benjamin (2012).

Nesse sentido o intelectual exerce um trabalho de intervenção na realidade, tanto ao atuar no viés político quanto no estético. Ele sempre desempenha um papel político até mesmo quando nega o seu próprio papel e, consequentemente, fortalece algum tipo de ideologia. Segundo Jean-Paul Sartre (1948), o escritor que não pauta um olhar crítico sobre a sociedade está fortalecendo a ideologia dominante.

O escritor que consente em fortalecer a ideologia vacilante está, pelo menos, consentindo: essa adesão voluntária a princípios que outrora governavam os espíritos sem serem percebidos, o liberta deles; ele já os supera e emerge, despeito de si mesmo, na solidão e na liberdade. (SARTRE, 1948, p.78) 
A posição do intelectual diante da realidade define sua perspectiva ideológica. Said comenta que os intelectuais estão presentes em todos os movimentos políticos que visam construir uma sociedade igualitária: "Cada região do mundo produziu seus intelectuais, e cada uma dessas formações é debatida e argumentada com uma paixão ardente. Não houve nenhuma grande revolução na história moderna sem intelectuais [...]" (2005, p.25). Posto isto, percebemos que o poeta-intelectual pode ser engajado tanto social quanto literariamente. Nessa última perspectiva, o intelectual rompe com as formas antigas de fazer literário.

Os intelectuais nos países africanos de língua portuguesa também cumprem esse papel de engajamento. Mia Couto (2008) comenta que o escritor que escreve em África, tem um papel que questiona a ordem, os estereótipos, os conceitos, as naturalizações e as predeterminações.

O nosso papel é o de criarmos os pressupostos de um pensamento mais nosso, para que a avaliação do nosso lugar e do nosso tempo deixe de ser feita a partir de categorias criadas pelos outros. E passarmos a interrogar aquilo que nos parece natural e inquestionável: conceitos como os direitos humanos, a democracia e a africanidade. (COUTO, 2008, p.59) 
À vista disso, os intelectuais possuem um importante papel no processo de desmistificação de certas categorias. Esse processo de desmistificação e, ao mesmo tempo, de reconstrução de conceitos, começa a ser formulado no período colonial. A palavra torna-se o instrumento de luta anticolonial dos poetas. Ela também é uma ferramenta que possibilita refletir sobre a realidade de castração vivida pelos homens que estavam em guerra contra o colonialismo.

Benjamin (2012) discorre sobre o emudecimento dos homens que voltavam da Primeira Guerra Mundial. Os homens iam para a batalha e "voltavam mudos [...] não mais ricos, e sim mais pobres em experiência comunicável» (2012, p.214). O fenômeno do emudecimento observado por Benjamin pode ser visto também no período das lutas pela independência nos países africanos de língua portuguesa, em que os guerrilheiros combatiam o colonialismo e se deparavam com a morte, com o sofrimento da guerra e, consequentemente, tornaram-se impossibilitados de se comunicarem, pela dor que foi gerada.

Nesse contexto doloroso, a linguagem surge para regenerar o homem e a comunicação. José Craveirinha, por exemplo, é um dos escritores que "reabilita" o mundo estilhaçado pela colonização através da linguagem. Segundo Marinei Almeida e Vera Maquêa: 
Ao estudarmos a obra de Craveirinha, observamos que vários de seus poemas, sobretudo da fase mais delicada frente à sua participação na luta pela libertação, realizam como verdadeiros espaços abertos a vários tipos de situações, de pessoas e de ambientes degradados por anos e anos de exploração e subjugação. Assim, Craveirinha mergulha em seu mundo com grande desejo de reabilitálo e através da arma poderosa que é a palavra, traz uma contribuição enorme no reconhecimento desse mundo. (2005, p.19)

O discurso "reabilitador" de Craveirinha é dotado de uma força ideológica típica dos intelectuais que subvertem a ordem. O desejo por um mundo livre da exploração e subjugação faz-se presente no uso das metáforas e imagens que representam o novo.

Nos países africanos de língua portuguesa, a luta pela liberdade - através das palavras - possui um caráter nacionalista. Logo, defender a liberdade significava defender um projeto de nação do povo moçambicano. Nesse sentido, uma estratégia de denunciar o presente de sofrimento e miséria foi inscrever o desejo pela mudança nos versos. Sobre essa literatura, Almeida e Maquêa afirmam que

[...] a literatura dessa geração marca um lugar de convergência, no qual coabitam criatividade e luta. A literatura, 
então, passa a ser um dos componentes centrais da luta pela identidade, uma vez que a literatura é uma das formas mais importantes de produção cultural através das quais um povo pode ser identificado. (ALMEIDA; MAQUEA, 2005, p.18)

A partir dessa citação é possível perceber que os intelectuais, e mais especificamente os poetas, levantam-se em gritos de resistência, por meio das artes, em defesa de um novo projeto de sociedade que pretendia fazer com que os moçambicanos se reconhecessem como nação.

O nacionalismo expresso nos versos é um elemento comum na produção literária dos autores desse período nos países africanos de língua portuguesa. Os elementos regionais, as personagens do dia-a-dia, o sofrimento e a miséria entram em cena como forma de denúncia, como podemos ler em "Poema" (1963, p.22) do cabo-verdiano Antônio Mendes Cardoso .

Na espuma verde
do mar
desenharei o teu nome,
Em cada areia
da praia
em cada pólen
da flor
em cada gota
do orvalho
o teu nome
deixarei gravado


No protesto calado

de cada homem ultrajado

em cada insulto

em cada folha caída

em cada boca faminta

hei-de escrever

o teu nome

No seios férteis

das virgens

nos sorrisos perenes

das mães

nos dedos dos namorados

no embrião da semente

na luz irreal das estrelas

nos limites do tempo

hei-de uma esperança semear.

A voz inscrita em primeira pessoa descreve o espaço que se constitui pela natureza ("praia", "flor", "orvalho", "semente", "estrelas") e pelos homens ("homem", "virgens", "mães", "namorados"). No entanto, durante a descrição do espaço, a voz poética cria uma relação entre parte e todo expressa em "espuma do mar", "areia da praia”, "pólen da flor", "gota do orvalho", "seios das virgens", "sorrisos das mães", "dedos dos namorados". O poeta funde as partes que se encontravam separadas, promovendo uma fusão entre homem ("virgens", "mães", "namorados") e natureza ("semente", "estrelas"), que passam a coabitar não apenas o espaço físico, mas também o espaço poético, formando uma totalidade. Ao criar essa correspondência, sugere a 
comunhão entre homem e natureza. Essa relação demonstra que ambos estão interligados em tempo e espaço. A natureza não é somente lugar onde se desenvolve o enredo, mas é também um ser vivo que compõe uma existência harmônica com o homem. Essa ligação pode ser analisada de forma política, visto que no mundo ocidental o homem é superior à natureza. O homem, centro do universo, modifica as coisas e não é modificado por elas. Em outras concepções de mundo, homem e natureza fazem parte de um mesmo universo, partilhando de uma absoluta alteridade com as coisas, com os seres.

O discurso da voz poética assume o futuro do presente como vemos nos verbos "desenharei", "deixarei" e "heide". A opção por esse tempo verbal reflete a posição do eu poético que não se renderá e continuará lutando. A luta ultrapassa o tempo presente, projetando-se ao longo da existência do homem.

De acordo com Bosi (2000), as palavras no universo poético projetam vontades e desejos por um mundo diferente da realidade vivida: "Projetando na consciência do leitor imagens do mundo e do homem muito mais vivas e reais do que as forjadas pelas ideologias, o poema acende o desejo de uma outra existência, mais livre e mais bela" 
(2000, p.227). Os poetas projetam imagens e metáforas nas consciências dos seus leitores. Anunciam o novo como forma de lutar por um futuro "mais livre". No poema, o futuro é semeado a cada palavra.

Além de projetar o futuro através da reafirmação da esperança, outro aspecto importante na poesia anticolonial é a crítica à colonização que se expressa ora como combate ao racismo, ora como reinvenção da tradição, ora como denúncia dos modelos europeus impostos às sociedades africanas. Em "Meu canto Europa", poema de Tomás Medeiros (1963, p.30), de São Tomé e Príncipe, nota-se a denúncia social presente nos versos.

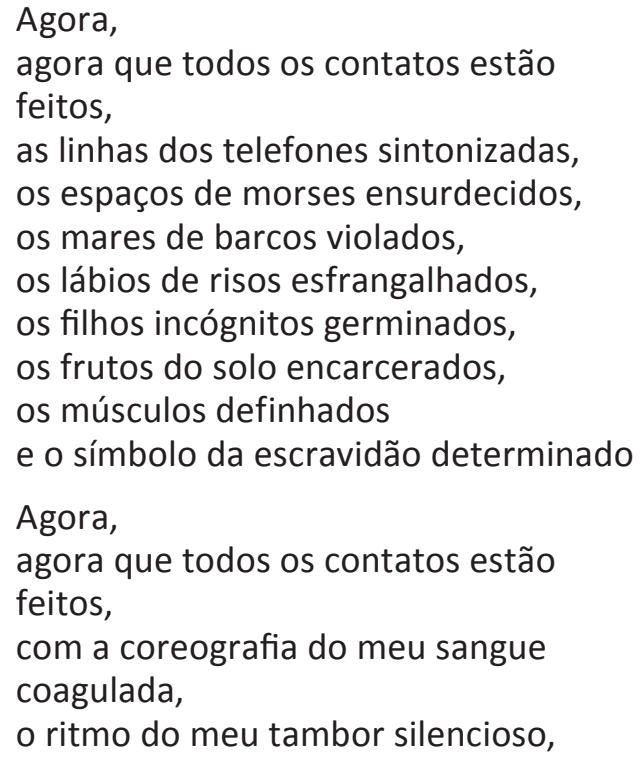


os fios do meu cabelo embranquecidos, meu coito denunciado e o esperma esterilizado, meus filhos de fome engravidados, minha ânsia e meu querer amordaçados, minhas estatuas de heróis dinamitadas, meu grito de paz com chicotes abafado, meus passos guiados como passos de besta, e o raciocínio embotado e manietado Agora, agora que me estampaste no rosto os primores de tua civilização, eu te pergunto, Europa, eu te pergunto: AGORA?

O advérbio "agora" (1o verso, 1aㅡ estrofe) marca o tempo do discurso (presente) da voz poética, como vemos nos verbos da primeira e da segunda estrofe. No entanto, ao longo do poema esses verbos passam a funcionar como predicativos, indicando estado. Essa relação entre ação e estado sugere que o próprio processo de colonização está consumado. O colonizador não precisa mais intervir na realidade, pois a colônia já assimilou a cultura e os costumes do colonizador. O espaço no qual o sujeito colonizado, demarcado pela voz poética, caminha foi degradado com o processo de colonização.

A repetição intensiva dos pronomes possessivos "meu", "meus", "minha" e "minhas" (2a estrofe) sugere que tudo aquilo que era propriedade do eu poético foi alterado pelo 
processo de colonização. Os símbolos de grande significado, a exemplo do "tambor" e das "estátuas", vão perdendo vida, sendo substituídos pelos símbolos do colonizador.

É possível perceber também a relação homem-natureza. Os elementos da primeira estrofe, "mares" (5ㅇv verso) e "frutos" (8o verso) estão em aliança com "lábios" (6으 verso), "filhos" (7o verso) e "músculos" (9o verso). O poeta tenta reabilitar o contato do homem com a natureza que foi rompido no processo de colonização, na medida em que a metrópole alienou o homem colonizado ao trabalho forçado. Retomar a natureza seria uma forma de resistir ao processo colonial. A ruptura promovida pelo mundo ocidental, no qual natureza e homem se separam, é descartada no espaço poético, assim, homem e natureza passam a coabitar os versos.

Na última estrofe, após a longa descrição do espaço desconfigurado e destruído, o eu poético questiona a metrópole e os objetivos do processo de colonização. O poema constrói-se a partir de uma denúncia do sistema colonial, pois expor as contradições é uma forma de combate e de luta contra a ordem. O escritor, inserido nas lutas pela libertação dos países africanos de língua portuguesa, envereda pelos caminhos da denúncia social como lemos nos 
poemas de Medeiros (1963) e Cardoso (1963). A resistência, que reside nos versos, está ligada à identidade.

Franz Fanon comenta que a identidade é uma espécie de imagem assumida, que é construída na relação eu-outro, sendo que só é possível ter "dignidade de espírito" (2008, p.181) nesse encontro.

Na sua imediaticidade, a consciência de si é simples ser para si. Para obter a certeza de si-mesmo, é preciso a integração do conceito de reconhecimento. O outro, igualmente, espera nosso reconhecimento, a fim de se expandir na consciência de si universal. Cada consciência de si procura o absoluto. Ela quer ser reconhecida enquanto valor primordial, desvinculado da vida, como transformação da certeza subjetiva (Gewisheit ${ }^{11}$ ) em verdade objetiva (Wahrheit ${ }^{12}$ ). (FANON, 2008, p.181)

Portanto, o outro é um elemento visceral na constituição do eu. É nessa "integração" que se constrói a identidade, sendo a mesma um conceito cambiável, pois o outro e eu estamos em constante transformação. No período colonial, mesmo com a denúncia à colonização, houve um reconhecimento do multiculturalismo presente nos países africanos de língua portuguesa. Os escritores buscavam

\footnotetext{
11 Consciência

12 Verdade
} 
referências no passado (tradição, oralidade, símbolos), mas também traçavam referências do colonizador, a exemplo da língua.

A busca de diferentes elementos surge do embate cultural. Segundo Homi Bhabha (1998), ocorre uma "negociação" que se expressa em conflito ou em consenso, que "é uma negociação complexa, em andamento, que procura conferir autoridade aos hibridismos culturais que emergem em momentos de transformação" (1998, p.21).

Essa negociação cultural se apresenta também na literatura no uso dos elementos que compõem o eu e o outro. Portanto, existe um nacionalismo que busca exaltar a terra e o homem que vive nela, mas, ao mesmo tempo, o patriotismo torna-se humanitário abrangendo um caráter que rompe com o locus em que a literatura é tecida. Logo, o nacional se instala como um dos elementos da identidade que é composta também do humanismo, da negritude e da alteridade. Para Mauricio Silva:

[...] se essa literatura nasce vinculada a um projeto mais amplo de luta anticolonial, o que lhe confere um caráter de literatura militante, utilizando-se do texto literário em favor de uma causa político-social independentista, com o passar do tempo e agora num plano fundamentalmente cultural, ela certamente se liga a um 
desígnio identitário e nacionalista, resultando, primeiro, na afirmação da identidade cultural local, com a valorização das singularidades nativas e comunitárias da região; e, depois, na criação de uma consciência nacionalista, incentivando a defesa de valores sociais humanitários. (SILVA, 2010, p.41)

A identidade, erigida no espaço poético, busca os elementos nacionais e humanitários. Reafirma o passado do colonizado e reconhece o presente permeado pela diferença cultural. Esse reconhecimento, entretanto, não quer dizer consentimento. A poética de José Craveirinha, por exemplo, reconhece a diferença e o hibridismo, mas não se omite em denunciar a colonização através da construção de imagens.

Quando o poeta opta pelos elementos da cultura de seu país, ele cria uma posição de ofensiva diante da realidade posta. Ao cultivar esses elementos tão próprios da sua cultura, posiciona-se como escritor que valoriza a cultura que foi subjugada, numa tentativa de reinvenção da alteridade. O poema de José Craveirinha (2008, p.79), "Canto do nosso amor sem fronteira", mostra a unidade almejada pelo eu poético.

Estamos juntos.

E moçambicanas mãos nossas

dão-se

e olhamos a paisagem e sorrimos. 
Não sabemos de áreas de esterlino de câmbios vistos de fronteira zonas de marco e dólar portagem do Limpopo canais de Suez e do Panamá.

Amamo-nos hoje numa praia das Honduras estamos amanhã sob o céu azul da Birmânia e na madrugada do dia dos teus anos despertamos nos braços um do outro baloiçando na rede da nossa casa na Nicarágua.

O poema abre-se com o verso "Estamos juntos" que possui o sujeito desinencial (nós) que se encontra na primeira pessoa do plural. A maioria dos verbos do poema também está disposta desta forma: "olhamos", "sabemos", "amamonos", "estamos", "despertamos". O uso do pronome pessoal (nós) sugere o sentimento de coletividade. O eu poético atua como "nós" poético gerando uma agremiação identitária e conclama todos a se darem as mãos. É nesse movimento de reconhecer-se com o outro, que os sujeitos poéticos cantam o amor pela terra e pelo povo.

As vozes poéticas restringem essa unidade aos moçambicanos, como vemos no uso do adjetivo "mãos moçambicanas". Dessa forma, demarcam seu território e reafirmam sua identidade. Entretanto, ao mesmo tempo, 
eles se deslocam do espaço moçambicano remetendo, na terceira estrofe, aos Canais de Suez (Egito), Panamá, Honduras, Birmânia (América Central) e Nicarágua (Ásia). Ao criar esse deslocamento, os sujeitos poéticos reafirmam uma identidade que não se restringe ao espaço moçambicano. Eles evocam os muitos moçambicanos que vivem em outros territórios e conclamam uma irmandade entre todos os povos que sofreram com a colonização. Nesse processo, desfazemse as fronteiras; o canto supera as demarcações impostas. Ao se reconhecerem, ainda que em espaços diferentes, encontram-se um no outro, formando uma grande extensão que se integra, mas que tem suas particularidades. Segundo Paz (1982, p.155), esse fenômeno pode ser chamado de "outridade". De acordo com ele: "O outro é algo que não é como nós, um ser que é também um não ser" (1982, p.156).

A poesia de Craveirinha é permeada por esse sentimento de "outridade" que se expressa no espaço poético. Os sujeitos poéticos estão espalhados em diferentes territórios, mas encontram-se no espaço poético. A união de vozes, no uso do sujeito desinencial "nós", constrói o canto expresso no título "Canto do nosso amor sem fronteira". Esse entrelaçamento de vozes promove o sentimento de coletividade.

$\mathrm{Ou}$

com os olhos incendiados 
nos poentes do Mediterrâneo recordamos as noites mornas da praia da Polana ${ }^{13}$

e a beijos sorvo a tua boca no Senegal e depois tingimos mutuamente os lábios com as negras amoras de Jerusálem ambos entristecidos ao galope dos pés humanos

sem ferraduras mas puxando riquexós só de ver puxar nós também puxamos nas transpiradas ruelas antigas da ilha de Moçambique.

Oh, beijemo-nos, amor teus cabelos sussurrantes na esplêndida nudez morena do meu peito que são nossos os céus sulcados de xiricos ${ }^{14}$ e aviões e nossos irmãos os povos dos outros paralelos até mesmo os pobres boers solitários na cruzada de amor em que me abraças numa rua principal da cidade de Pretóra descontraidamente como se fosse no bairro do Xipamine ${ }^{15}$.

Mas bem fundo das almas e dos corpos tatuados de esperança o clitóris das montanhas nos sexos das nuvens pátria do nosso desespero mais desesperado

\footnotetext{
13 Praia localizada em Moçambique

14 Xirico designa pássaro amarelo

15 Bairro pobre
} 
pátria dos pés descalços na brancura do algodão pátria de beijos e promessas de mais beijos é o nosso genuíno grito mais gritado a levantar no cosmos a beleza do nome não renegável de Moçambique!

A relação erotismo-natureza está marcada nos versos acima. Numa tentativa de deslocar o homem do centro do universo, o poeta opera uma inversão dos corpos. O erótico estaria ligado à natureza, pois tem relação com o divino e o místico. Seguindo um viés panteísta, a natureza seria a verdadeira fonte de libertação do homem. A natureza, então, quase se confunde com o homem. Assim, corpo e alma, concreto e abstrato, divino e profano se (inter)relacionam na poesia. A relação corpo-alma é uma unidade correspondente nos versos do poeta. O homem seria a representação do corpo, e a natureza, da alma. Unidas no espaço poético, elas reabilitam a cisão que o mundo ocidental operou. A divisão entre homem e natureza vai ser apagada, dando lugar a uma unidade correspondente entre eles. Além do corpo do homem, a natureza se torna corpo assumindo características humanas. Ao falar da natureza como corpo, o poeta insere, no fazer poético, elementos da sua cultura recorrendo à natureza e aos animais, como símbolos para explicar o mundo e os homens. Nessa concepção, a natureza não seria 
um ser que imita o homem, como sugere a personificação, mas um ser orgânico e autônomo.

A redundância marcada na última estrofe sugere uma estratégia para inflamar o desejo pela liberdade intensificando o "desespero" e o "grito". O sentimento de angústia precisa ser reafirmado pelo eu poético.

O uso da anáfora "pátria" pode reafirmar a necessidade de liberdade e constrói um tom de nacionalismo, que se confirma nos dois últimos versos do poema "a levantar no cosmos a beleza do nome/ não renegável de Moçambique!". De acordo com Mendonça (2002, p.53), o poeta José Craveirinha "vai irromper na nossa literatura escrita através da afirmação nacional, que a recriação poética transforma em apoteose verbal em [...] orgia da língua e da palavra". Portanto, o nacionalismo faz-se presente na reafirmação da "pátria", mas também no uso das expressões vocabulares.

A poética dos escritores do período das lutas pela independência é marcada pela resistência e pelo desejo de um novo mundo. Ao recorrer ao passado, os poetas projetam o futuro, enquanto refletem sobre o presente de castração e sofrimento. A poesia anticolonial é também uma arma de luta. O verso é trincheira; a palavra é arma. A resistência política está em consonância com a resistência literária, à 
medida que a luta se estabelece no campo objetivo (luta armada, guerrilha, território), mas também no campo ideológico e simbólico (literatura, arte, teoria).

\section{REFERÊNCIAS}

ALMEIDA, Marinei; MAQUEA, Vera (2005). José Craveirinha e Mia Couto: utopia e construção do espaço nacional em África. Revista Ecos. Cáceres: n.3, p.16-23.

BENJAMIN, Walter (2012). Magia, arte, técnica e política: ensaios sobre literatura e história da cultura. São Paulo: Brasiliense.

BHABHA, Homi (1998). O local da cultura. Belo Horizonte: Editora Ufmg. BOSI, Alfredo (2000). O ser e o tempo da poesia. São Paulo: Companhia das Letras.

CABAÇO, José Luís (2009). Moçambique: identidade, colonialismo e libertação. São Paulo: Editora Unesp.

CARDOSO, Antônio Mendes (1963). "Poema". In: NEVES, João Alves das. Poetas e contistas africanos de expressão portuguesa. São Paulo: Editora Brasiliense.

COUTO, Mia (2008). Pensatempos: textos de opinião. Portugal: Editora Caminho .

CRAVEIRINHA, José (2008). Karingana ua Karingana. Maputo: Alcance Editores.

FANON, Frantz (2008). Pele negra, máscaras brancas. Salvador: Edufba. LEITE, Ana Mafalda (1991). A poética de José Craveirinha. São Paulo: Vega. MEDEIROS, Tomas (1963). "Meu canto Europa”. In: NEVES, João Alves das. Poetas e contistas africanos de expressão portuguesa. São Paulo: Editora Brasiliense.

MENDONÇA, Fátima (2002). O conceito de nação em José Craveirinha, Rui Knopfli e Sérgio Vieira. Via Atlântica. São Paulo: n.5, p.52-66.

PAZ, Octavio (1982). O arco e a lira. Rio de Janeiro: Nova Fronteira. 
SAID, Edward W (2005). Representações do intelectual: as Conferências Reiht de 1993. São Paulo: Companhia das Letras.

SARTRE, Jean-Paul (1993). Que é a Literatura? São Paulo. Ática.

SILVA, Mauricio (2010). Identidade cultural e consciência nacionalista nas literaturas africanas lusófonas: uma introdução. Revista Ipotesi. Juiz de fora:14(4), p.39 43.

Luana Soares de Souza é Doutoranda em Estudos Literários pela Universidade do Estado de Mato Grosso, campus Tangará da Serra lusoares90@gmail.com 